\title{
Trimeric Radiofluorinated Sulfonamide Derivatives to Achieve In Vivo Selectivity for Carbonic Anhydrase IX-Targeted PET Imaging
}

\author{
Joseph Lau*1, Zhibo Liu*2, Kuo-Shyan Lin ${ }^{1}$, Jinhe Pan ${ }^{1}$, Zhengxing Zhang ${ }^{1}$, Daniela Vullo ${ }^{3}$, Claudiu T. Supuran ${ }^{3}$, \\ David M. Perrin ${ }^{2}$, and François Bénard ${ }^{1}$ \\ ${ }^{I}$ Department of Molecular Oncology, BC Cancer Agency, Vancouver, British Columbia, Canada; ${ }^{2}$ Chemistry Department, University \\ of British Columbia, Vancouver, British Columbia, Canada; and ${ }^{3}$ Università degli Studi di Firenze, Dipartimento Neurofarba and \\ Laboratorio di Chimica Bioinorganica, Florence, Italy
}

\begin{abstract}
Carbonic anhydrase IX (CA-IX), a transmembrane enzyme, mediates cell survival under hypoxic conditions and is overexpressed in solid malignancies. In this study, we synthesized four ${ }^{18} \mathrm{~F}$ sulfonamide derivatives and evaluated their potential for imaging CA-IX expression with PET. Methods: Azide derivatives of 2 carbonic anhydrase inhibitors, 4-(2-aminoethyl)benzenesulfonamide (AEBS) and 4-aminobenzensulfonamide (ABS), were coupled to radiosynthons with either 1 or 3 alkynes and a pendent ammoniomethyltrifluoroborate $\left(\mathrm{AmBF}_{3}\right)$ to generate monovalent or trivalent enzyme inhibitors. Binding affinity to CA-IX and other CA isoforms was determined via a stopped-flow, $\mathrm{CA}$-catalyzed $\mathrm{CO}_{2}$ hydration assay. Tracers were radiolabeled via ${ }^{18} \mathrm{~F}-{ }^{19} \mathrm{~F}$ isotope exchange reactions. Imaging/biodistribution studies were performed using HT-29 tumor-bearing immunocompromised mice. Results: Monomeric $\mathrm{AmBF}_{3}-\mathrm{AEBS}$ and $\mathrm{AmBF}_{3}-\mathrm{ABS}$ were obtained in $41 \%$ and $40 \%$ yields, whereas trimeric $\mathrm{AmBF}_{3}$-(AEBS) and $\mathrm{AmBF}_{3}-(\mathrm{ABS})_{3}$ were obtained in $47 \%$ and $55 \%$ yields, respectively. Derivatives bound CA-I, -II, -IX, and -XII with good affinity (0.49-100.3 nM). ${ }^{18}$ F-labeled sulfonamides were obtained in $16.3 \%-$ $36.8 \%$ non-decay-corrected radiochemical yields, with $40-207 \mathrm{GBq} /$ $\mu \mathrm{mol}$ specific activity and greater than $95 \%$ radiochemical purity. Biodistribution/imaging studies showed that the tracers were excreted through both renal and hepatobiliary pathways. At $1 \mathrm{~h}$ after injection, HT-29 tumor xenografts were clearly visualized in PET images with modest contrast for all 4 tracers. Tumor uptake was 2-fold higher for monovalent tracers $(\sim 0.60$ percentage injected dose per gram $[\% / D / g])$ than for trivalent tracers $(\sim 0.30 \% \mathrm{ID} / \mathrm{g})$; however, tumor-to-background ratios were significantly better for ${ }^{18} \mathrm{~F}-\mathrm{AmBF}_{3}-(\mathrm{ABS})_{3}$. Preblocking with acetazolamide reduced more than $80 \%$ uptake of ${ }^{18} \mathrm{~F}_{-} \mathrm{AmBF}_{3}$ $(A B S)_{3}$ in HT-29 tumors. Conclusion: Our data suggest that trimerization of an otherwise nonspecific CA inhibitor greatly enhances the selectivity for CA-IX in vivo and represents a promising strategy for creating multivalent enzyme inhibitors for selectively imaging extracellular enzyme activity by PET.
\end{abstract}

Received Jan. 6, 2015; revision accepted Jul. 9, 2015.

For correspondence or reprints contact either of the following:

Kuo-Shyan Lin, Department of Molecular Oncology, BC Cancer Agency,

Vancouver BC, Canada.

E-mail: klin@bccrc.ca

David M. Perrin, Chemistry Department, University of British Columbia, Vancouver BC, Canada.

E-mail: dperrin@chem.ubc.ca

${ }^{*}$ Contributed equally to this work.

Published online Jul. 23, 2015.

COPYRIGHT (c) 2015 by the Society of Nuclear Medicine and Molecular Imaging, Inc.
Key Words: positron emission tomography; hypoxia; carbonic anhydrase IX; one-step ${ }^{18} \mathrm{~F}$-labeling; ${ }^{18} \mathrm{~F}-\mathrm{AmBF}_{3}$

J Nucl Med 2015; 56:1434-1440

DOI: 10.2967/jnumed.114.153288

\section{$\mathbf{P}$}

ET imaging plays an increasingly important role in noninvasively characterizing tumor subtypes to inform drug development and evaluate drug target expression, in vivo. Extracellular targets are typically imaged with radiolabeled peptides, aptamers, and antibodies. Small molecules (e.g., ${ }^{18} \mathrm{~F}$-fluoromisonidazole, ${ }^{18} \mathrm{~F}$-fluorothymidine, and a host of others) have been used to probe enzymatic activity that may be associated within a given cell type. Nevertheless, the application of small-molecule inhibitors as PET tracers can be challenged by several effects such as nonspecific uptake in cells, poor clearance from blood (1), and rapid metabolic defluorination with accompanying bone uptake $(2,3)$. In addition, ${ }^{18} \mathrm{~F}$ labeling in high yield and at high specific activity often presents a significant challenge in the development of new PET tracers (4).

Yet even when conditions for clinically useful radiolabeling have been met, nonspecific uptake due to association with off-target enzyme isoforms of greater abundance can result in images marked by low tumor-to-background ratios. Lipophilicity can also enhance nonspecific uptake in some cases. We hypothesized that a multivalent enzyme inhibitor would restrict intracellular accumulation and enhance specific binding to an extracellular tumor target. To accomplish this, we used a radiosynthon that readily enables grafting of various ligands to a pentaerythritol core while allowing for facile radiolabeling at high specific activity with Curie levels of ${ }^{18} \mathrm{~F}$ activity. Recently, we communicated this method for linking both peptides and small-molecule inhibitors in a trivalent motif (5). Here we expand the application of this method to address the imaging potential of 2 related enzyme inhibitors and report detailed findings on how this method can be used to reduce nonspecific intracellular accumulation.

Toward these ends, we sought to image carbonic anhydrase IX (CA-IX), which is differentially expressed in tumors under hypoxia and therefore of great clinical interest $(6,7)$. This transmembrane enzyme represents a considerable challenge because of ubiquitously expressed isoforms that otherwise compete with known inhibitors, leading to high background and often low if not unobserved tumor uptake (vide infra). Regulated by hypoxia-inducible factor $1 \alpha$, CA-IX 
is involved in, among others, maintaining an alkaline intracellular $\mathrm{pH}$ while acidifying the extracellular environment. The latter process facilitates cell migration and invasion and potentiates metastatic activity in primary lesions $(8,9)$. Recently, CA-IX has been shown to mediate growth and expansion of breast cancer stem cells within hypoxic niches (10). Clinically, the expression of CA-IX is negatively correlated with patient prognosis and survival (11). In addition to breast cancer, CA-IX is overexpressed in many other solid malignancies including lung, colon, cervix, ovary, head and neck, bladder, and renal cancers (11). With limited expression in normal tissues (12-14), CA-IX represents an attractive target for therapy, with a sulfonamide inhibitor in early phase I clinical trial (ClinicalTrails.gov: safety study of SLC-0111 in subjects with advanced solid tumors).

Compared with therapeutics, the development of imaging agents to quantify expression of CA-IX is still in its early stages. Monoclonal antibodies and small-molecule inhibitors have been explored for nuclear imaging. ${ }^{124} \mathrm{I}-\mathrm{cG} 250$, a monoclonal antibody targeting the PG-like domain of CA-IX, advanced to phase III clinical trial for the diagnosis of clear cell renal cell carcinoma (marketed as RENAREX by WILEX AG) (15). Because of concerns with tumor penetrance within hypoxic regions and nonideal delayed imaging, research groups have sought alternatives to monoclonal antibody-based imaging. Indeed, one coumarin and several sulfonamides have been radiolabeled for targeting CA-IX (Fig. 1) (16-24). Although these tracers are potent CA-IX inhibitors, those that were evaluated in vivo $(18-21)$ suffered from low tumor uptake, selectivity, or stability (Table 1).

Our previous attempt using ${ }^{18} \mathrm{~F}-\mathrm{U}-104$ (compound $\mathrm{H}$ ) resulted in high uptake in blood (13.97 \pm 3.07 percentage injected dose per gram $[\% \mathrm{ID} / \mathrm{g}]$ at $1 \mathrm{~h}$ after injection) (21) presumably because of the binding of ${ }^{18} \mathrm{~F}-\mathrm{U}-104$ to intracellular off targets CA-I and CA-II that are abundant in erythrocytes (25). We hypothesized that cellimpermeant tracers would disfavor binding to intracellular CA isoforms and in turn provide high-contrast images. To achieve cell impermeabilitiy, we sought multivalent inhibitors to increase both avidity and molecular weight. In the present study, we synthesized and evaluated 2 monomeric (as controls) and 2 trimeric ${ }^{18} \mathrm{~F}$-labeled sulfonamides using 4-(2-aminoethyl)benzenesulfonamide (AEBS) and 4-aminobenzensulfonamide (ABS) as our pharmacophores for imaging CA-IX expression with PET. In terms of a radioprosthetic group, we chose the zwitterionic organotrifluoroborate (5), the polarity of which would likely further reduce lipophilicity and membrane permeability.

\section{MATERIALS AND METHODS}

Information for reagents, instruments, affinity measurements, radiochemistry, $\log \mathrm{D}_{7.4}$ measurements, plasma stability studies, PET imaging experiments, and data analysis are provided in the supplemental materials (supplemental materials are available at http://jnm.snmjournals. org). All animal studies were performed in accordance with the Canadian Council on Animal Care guidelines and approved by the Animal Care Committee of the University of British Columbia.

\section{RESULTS}

\section{Chemistry and Radiochemistry}

The preparation of nonradioactive ${ }^{19} \mathrm{~F}-\mathrm{AmBF}_{3}-\mathrm{AEBS},{ }^{19} \mathrm{~F}-$ $\mathrm{AmBF}_{3}-\mathrm{ABS},{ }^{19} \mathrm{~F}-\mathrm{AmBF}_{3}-(\mathrm{AEBS})_{3}$, and ${ }^{19} \mathrm{~F}-\mathrm{AmBF}_{3}-(\mathrm{ABS})_{3}$ followed synthetic schemes as shown in Figure 2. Azidoacetyl-AEBS 1 was obtained in $74 \%$ yield by coupling AEBS with azidoacetic acid, whereas azidoacetyl-ABS 2 was prepared in $60 \%$ yield by the displacement of the chloro group of 2-chloro- $N$-(4-sulfamoyl-phenyl)acetamide with azide. The coupling of $\mathbf{1}$ and $\mathbf{2}$ to $\mathrm{AmBF}_{3}$-conjugated alkyne 3 via the $\mathrm{Cu}^{+}$-catalyzed click reaction afforded the desired $\mathrm{AmBF}_{3}-\mathrm{AEBS}$ and $\mathrm{AmBF}_{3}-\mathrm{ABS}$ in $41 \%$ and $40 \%$ yields, whereas coupling to alkyne 4 generated $\mathrm{AmBF}_{3}-(\mathrm{AEBS})_{3}$ and $\mathrm{AmBF}_{3}-(\mathrm{ABS})_{3}$ in $47 \%$ and $55 \%$ yields, respectively.

The ${ }^{18} \mathrm{~F}$-labeling reactions were performed via ${ }^{18} \mathrm{~F}-{ }^{19} \mathrm{~F}$ isotope exchange as depicted in Figure 3. Starting with 23.3-38.5 GBq of ${ }^{18} \mathrm{~F}$-fluoride, ${ }^{18} \mathrm{~F}-\mathrm{AmBF}_{3}-\mathrm{AEBS},{ }^{18} \mathrm{~F}-\mathrm{AmBF}_{3}$ $\mathrm{ABS},{ }^{18} \mathrm{~F}-\mathrm{AmBF}_{3}-(\mathrm{AEBS})_{3}$, and ${ }^{18} \mathrm{~F}-\mathrm{AmBF}_{3}-$ $(\mathrm{ABS})_{3}$ were obtained in $24.8 \% \pm 2.2 \%$, $26.4 \% \pm 10.2 \%, 28.0 \% \pm 3.5 \%$, and $26.9 \% \pm 5.6 \%$ non-decay-corrected radiochemical yields $(n=3)$ with corresponding specific activities of $185 \pm 22,141 \pm$ $11,66 \pm 9$, and $49 \pm 12 \mathrm{GBq} / \mu \mathrm{mol}$, respectively. After C18 Sep-Pak (Waters) purification, more than $95 \%$ radiochemical purity was obtained for all tracers based on high-performance liquid chromatography radiochromatograms.

\section{Binding Affinity $\left(\mathrm{K}_{\mathrm{i}}\right)$ to $\mathrm{CA}$ Isoforms}

The binding affinities of the synthesized compounds to CA-I, -II, -IX, and -XII are summarized in Table 2. $\mathrm{K}_{\mathrm{i}}$ values to CA-IX for $\mathrm{AmBF}_{3}-\mathrm{AEBS}, \mathrm{AmBF}_{3}-\mathrm{ABS}, \mathrm{AmBF}_{3}-$ $(\mathrm{AEBS})_{3}$, and $\mathrm{AmBF}_{3}-(\mathrm{ABS})_{3}$ were 8.0, $6.0,35.7$, and $8.5 \mathrm{nM}$, respectively. Acetazolamide, a pan-CA inhibitor $(8,26)$, was included as a positive control.

\section{Plasma Stability and Lipophilicity}

To assess stability, tracers were incubated in mouse plasma and analyzed by
FIGURE 1. Reported radiolabeled small-molecule inhibitors for CA-IX imaging. Compound $\mathrm{A}-\mathrm{M}$ are sulfonamide-based derivatives, whereas compound $\mathrm{N}$ is a coumarin-based inhibitor. 
TABLE 1

Summary of Biologic Evaluation Data of Radiolabeled CA-IX Imaging Probes Shown in Figure 1

\begin{tabular}{|c|c|c|c|c|c|c|c|}
\hline \multirow[b]{2}{*}{ Compound } & \multirow[b]{2}{*}{$\begin{array}{c}\text { Binding affinity } \\
\qquad \mathrm{K}_{\mathrm{i}}(\mathrm{nM})\end{array}$} & \multicolumn{4}{|c|}{ Biodistribution } & \multirow[b]{2}{*}{ Imaging data } & \multirow[b]{2}{*}{ Reference } \\
\hline & & Tumor model & $\begin{array}{l}\text { Tumor uptake } \\
\text { (\%ID/g) }\end{array}$ & $\begin{array}{l}\text { Tumor-to- } \\
\text { blood ratio }\end{array}$ & $\begin{array}{l}\text { Tumor-to- } \\
\text { muscle ratio }\end{array}$ & & \\
\hline$A$ & NA & NA & NA & NA & NA & NA & 16 \\
\hline $\mathrm{B}$ & 58 & HT-29 & 0.13 at $0.5 \mathrm{~h}$ & 0.75 at $0.5 \mathrm{~h}$ & NA & NA & 19 \\
\hline $\mathrm{C}$ & 59 & HT-29 & $0.2-0.1$ at $0.5-4 \mathrm{~h}$ & 0.0 at $0.5-4 \mathrm{~h}$ & NA & NA & 18 \\
\hline $\mathrm{D}$ & 66 & HT-29 & $0.5-0.1$ at $0.5-4 \mathrm{~h}$ & $0.4-0.5$ at $0.5-4 \mathrm{~h}$ & NA & NA & 18 \\
\hline$E$ & NA & HT-29 & $\leq 0.1$ at $0.5-4 \mathrm{~h}$ & $\leq 1.0$ at $0.5-4 \mathrm{~h}$ & NA & NA & 18 \\
\hline $\mathrm{F}$ & NA & HT-29 & $\leq 0.2$ at $0.5-4 \mathrm{~h}$ & $0.2-1.0$ at $0.5-4 \mathrm{~h}$ & NA & NA & 18 \\
\hline \multirow[t]{3}{*}{$\mathrm{G}$} & $0.9\left(R=3-\mathrm{NO}_{2}\right)$ & NA & NA & NA & NA & NA & 22 \\
\hline & $5.4(R=4-\mathrm{Ac})$ & NA & NA & NA & NA & NA & 22 \\
\hline & $0.3(R=2-\mathrm{CN})$ & NA & NA & NA & NA & NA & 22 \\
\hline $\mathrm{H}$ & 45 & HT-29 & 0.83 at $1 \mathrm{~h}$ & $<1.0$ at $1 \mathrm{~h}$ & $<1.0$ at $1 \mathrm{~h}$ & NA & 21 \\
\hline 1 & 124 & HT-29, U373 & $<0.25$ at $2-4 \mathrm{~h}$ & NA & NA & $\begin{array}{c}\text { No tumor } \\
\text { visualization }\end{array}$ & 39 \\
\hline $\mathrm{J}$ & 9.0 & NA & NA & NA & NA & NA & 23 \\
\hline \multirow[t]{3}{*}{$\mathrm{K}$} & $9.3(R=\mathrm{Me})$ & HT-29 & 0.51 at $1 \mathrm{~h}$ & $\sim 1.0$ at $1 \mathrm{~h}$ & $\sim 1.0$ at $1 \mathrm{~h}$ & $\begin{array}{c}\text { No tumor } \\
\text { visualization }\end{array}$ & 20 \\
\hline & $9.6(R=\mathrm{Ac})$ & HT-29 & 0.59 at $1 \mathrm{~h}$ & $\sim 1.0$ at $1 \mathrm{~h}$ & $\sim 1.0$ at $1 \mathrm{~h}$ & $\begin{array}{c}\text { No tumor } \\
\text { visualization }\end{array}$ & 20 \\
\hline & $9.1(R=\mathrm{Cl})$ & HT-29 & 0.98 at $1 \mathrm{~h}$ & $\sim 1.0$ at $1 \mathrm{~h}$ & $\sim 1.0$ at $1 \mathrm{~h}$ & $\begin{array}{c}\text { No tumor } \\
\text { visualization }\end{array}$ & 20 \\
\hline $\mathrm{L}$ & 5.2 & NA & NA & NA & NA & NA & 24 \\
\hline M & 7.0 & NA & NA & NA & NA & NA & 24 \\
\hline $\mathrm{N}$ & 70 & HT-29 & 1.16 at $1 \mathrm{~h}$ & $<1.0$ at $1 \mathrm{~h}$ & $\sim 1.0$ at $1 \mathrm{~h}$ & $\begin{array}{c}\text { No tumor } \\
\text { visualization }\end{array}$ & 21 \\
\hline
\end{tabular}

high-performance liquid chromatography. No metabolites of ${ }^{18} \mathrm{~F}-\mathrm{AmBF}_{3}-\mathrm{AEBS},{ }^{18} \mathrm{~F}-\mathrm{AmBF}_{3}-\mathrm{ABS},{ }^{18} \mathrm{~F}-\mathrm{AmBF} \mathrm{m}_{3}-(\mathrm{AEBS})_{3}$, and ${ }^{18} \mathrm{~F}-\mathrm{AmBF}_{3}-(\mathrm{ABS})_{3}$ were observed after $2 \mathrm{~h}$ incubation at $37^{\circ} \mathrm{C}$. The $\log \mathrm{D}_{7.4}$ ( $\mathrm{D}$ is the distribution coefficient at $\mathrm{pH} 7.4$ ) values for ${ }^{18} \mathrm{~F}-\mathrm{AmBF}_{3}-\mathrm{AEBS},{ }^{18} \mathrm{~F}-\mathrm{AmBF}_{3}-\mathrm{ABS},{ }^{18} \mathrm{~F}-\mathrm{AmBF}_{3}-$ $(\mathrm{AEBS})_{3}$, and ${ }^{18} \mathrm{~F}-\mathrm{AmBF}_{3}-(\mathrm{ABS})_{3}$ were $-1.9,-1.8,-2.1$, and -2.5 , respectively, using the shake flask extraction method.

\section{Biodistribution Studies}

Biodistribution data are summarized in Table $3 .{ }^{18} \mathrm{~F}-\mathrm{AmBF}_{3}-$ AEBS, ${ }^{18} \mathrm{~F}-\mathrm{AmBF}_{3}-\mathrm{ABS},{ }^{18} \mathrm{~F}-\mathrm{AmBF}_{3}-(\mathrm{AEBS})_{3}$, and ${ }^{18} \mathrm{~F}-\mathrm{AmBF}_{3^{-}}$ $(\mathrm{ABS})_{3}$ were cleared through hepatobiliary and renal pathways with generally low uptake in nonexcretory tissues including bone. Uptake in HT-29 tumor xenografts was approximately 2-fold higher for the monomers $(0.56-0.64 \% \mathrm{ID} / \mathrm{g})$ than the trimers (0.30-0.33\% \% /g). Notably, 5-fold-higher activity was observed in the blood $(0.51-0.56 \% \mathrm{ID} / \mathrm{g})$ for ${ }^{18} \mathrm{~F}-\mathrm{AmBF}_{3}-\mathrm{AEBS}$ and ${ }^{18} \mathrm{~F}-$ $\mathrm{AmBF}_{3}-\mathrm{ABS}$ than ${ }^{18} \mathrm{~F}-\mathrm{AmBF}_{3}-(\mathrm{AEBS})_{3}$ and ${ }^{18} \mathrm{~F}-\mathrm{AmBF}_{3}-(\mathrm{ABS})_{3}$ $(0.07-0.09 \% \mathrm{ID} / \mathrm{g})$, indicating slower clearance profiles or enhanced nonspecific binding. At $1 \mathrm{~h}$ after injection, the highest tumor-to-blood and tumor-to-muscle ratios (3.93 \pm 1.26 and $9.55 \pm 2.96$, respectively) were obtained when administering ${ }^{18} \mathrm{~F}_{-} \mathrm{AmBF}_{3}-(\mathrm{ABS})_{3}$. Preinjection with $10 \mathrm{mg}$ of acetazolamide per kilogram significantly reduced the uptake of ${ }^{18} \mathrm{~F}-\mathrm{AmBF}_{3}-(\mathrm{ABS})_{3}$ in tumors to $0.06 \pm 0.01 \% \mathrm{ID} / \mathrm{g}$, as well as its tumor-to-background ratios.

\section{PET/CT Imaging}

PET/CT images obtained at $1 \mathrm{~h}$ after injection (Figs. 4 and 5) were consistent with the biodistribution data. Higher uptake was observed in the kidneys, liver, and gastrointestinal tract. HT-29 tumor xenografts were clearly visualized after injecting ${ }^{18} \mathrm{~F}-\mathrm{AmBF}_{3^{-}}$ AEBS (Fig. 4A), ${ }^{18} \mathrm{~F}-\mathrm{AmBF}_{3}$-ABS (Fig. 4B), ${ }^{18} \mathrm{~F}-\mathrm{AmBF}_{3}-(\mathrm{AEBS})_{3}$

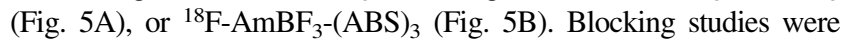
performed for ${ }^{18} \mathrm{~F}-\mathrm{AmBF}_{3}-(\mathrm{ABS})_{3}$ that generated highest tumorto-background contrast. Preinjection of acetazolamide effectively blocked uptake of ${ }^{18} \mathrm{~F}-\mathrm{AmBF}_{3}-(\mathrm{ABS})_{3}$ in the tumor and reduced tumor-to-background contrast (Fig. 5C).

\section{DISCUSSION}

The highly conserved catalytic domain of CA isoforms represents a major challenge for the design of CA-IX-selective imaging agents (6). Off-target binding to intracellular CAs can significantly reduce tumor binding and image contrast (25). Strategies to confer CA-IX selectivity for small-molecule inhibitors have focused on limiting transport across the plasma membrane. These include incorporating bulky entities such as fluorescein isothiocyanate, albumin binders, 


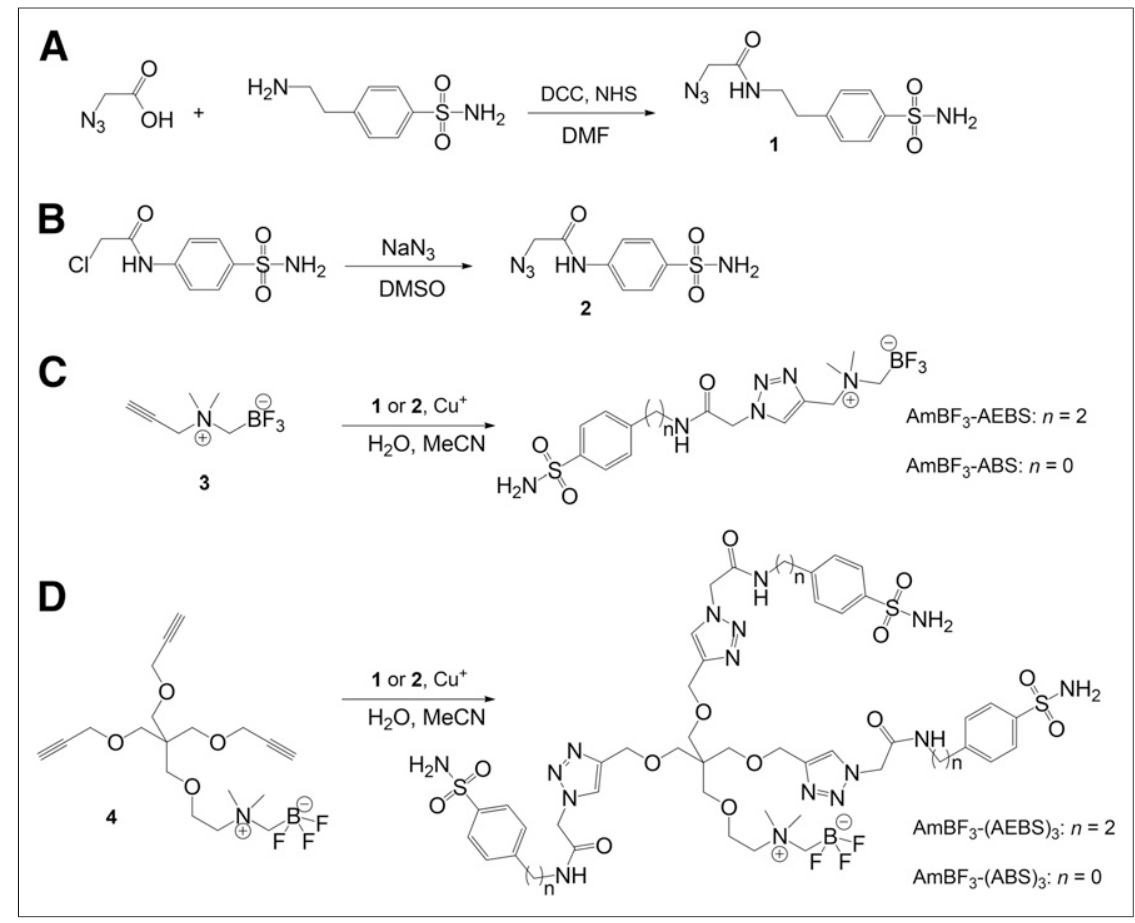

FIGURE 2. Synthesis of azidoacetyl-AEBS 1 (A), azidoacetyl-ABS $2(B), A^{2} B F_{3}-A E B S$ and $\mathrm{AmBF}_{3}-\mathrm{ABS}(\mathrm{C})$, and $\mathrm{AmBF}_{3}-(\mathrm{AEBS})_{3}$ and $\mathrm{AmBF}_{3}-(\mathrm{ABS})_{3}(\mathrm{D}) . \mathrm{DCC}=\mathrm{N}, \mathrm{N}^{\prime}$-dicyclohexylcarbodiimine; NHS $=N$-hydroxysuccinimde.

sugar derivatives, or charged species to CA-targeting pharmacophores (26-30). On the basis of these findings, we initiated the development of multivalent PET tracers for imaging CA-IX expression in tumors.

Previously, our group reported the synthesis of a dual-mode imaging agent by coupling rhodamine and cycloRGD (arginineglycine-aspartic acid) to an $\mathrm{AmBF}_{3}$-conjugated alkyne $\mathbf{4}$ amenable to ${ }^{18} \mathrm{~F}$ labeling (31). Using the modular adaptability of this synthon, we coupled 3 AEBS/ABS moieties via copper-catalyzed azide alkyne cycloaddition to target CA-IX expression. To the best of our knowledge, there are few examples of such multimeric inhibitors that have been labeled for imaging, and none has been labeled with ${ }^{18} \mathrm{~F}$-fluoride nor used to visualize tumor-associated CA-IX activity. For comparison and as controls, we coupled AEBS/ABS to $\mathrm{AmBF}_{3}$-conjugated alkyne 3 to synthesize mono-

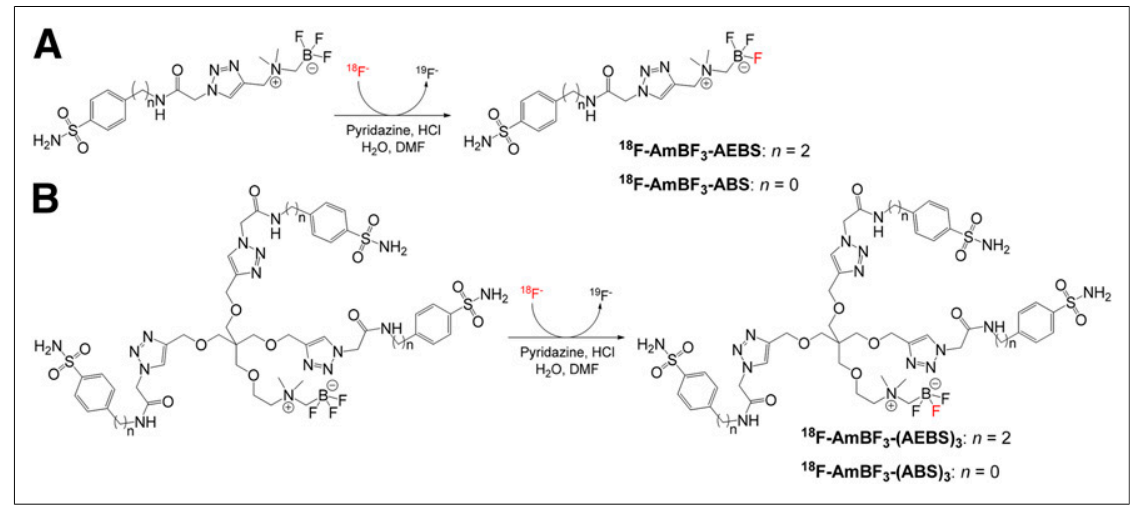

FIGURE 3. Radiosynthesis of ${ }^{18} \mathrm{~F}-\mathrm{AmBF}_{3}-\mathrm{AEBS}$ and ${ }^{18} \mathrm{~F}-\mathrm{AmBF}_{3}-\mathrm{ABS}(\mathrm{A})$ and ${ }^{18} \mathrm{~F}-\mathrm{AmBF}_{3}$ $(\mathrm{AEBS})_{3}$ and ${ }^{18} \mathrm{~F}-\mathrm{AmBF}_{3}-(\mathrm{ABS})_{3}(\mathrm{~B})$ via ${ }^{18} \mathrm{~F}-{ }^{19} \mathrm{~F}$ isotope exchange reaction. valent tracers to determine whether trimerization is essential to selectively target CA-IX in vivo.

Whereas more specific inhibitors can be designed to enhance selectivity to CA-IX, we sought to test the use of a trivalent scaffold with simple and rather nonspecific inhibitors to demonstrate that in vivo selectivity can be generated simply by altering cell permeability of the tracer to reduce uptake in the blood. AEBS and ABS are known to inhibit CA-IX; however, they by themselves lack isoform selectivity. According to the literature, the $\mathrm{K}_{\mathrm{i}}$ values of AEBS and ABS for CA-IX are 33 and $294 \mathrm{nM}$, respectively (32-34). For reasons unknown, incorporation of AEBS or $\mathrm{ABS}$ into $\mathrm{AmBF}_{3}$-conjugated radiosynthons resulted in consistent or significantly improved binding affinities for CA-IX. $\mathrm{AmBF}_{3}-\mathrm{AEBS}$ and $\mathrm{AmBF}_{3}-\mathrm{ABS}$ exhibited binding affinities of 8.0 and $6.6 \mathrm{nM}$, whereas $\mathrm{AmBF}_{3}-(\mathrm{AEBS})_{3}$ and $\mathrm{AmBF}_{3}$ $(\mathrm{ABS})_{3}$ had binding affinities of 35.7 and $8.5 \mathrm{nM}$. Despite retaining good binding affinity to CA-I and -II, the in vivo binding of bulky ${ }^{18} \mathrm{~F}-\mathrm{AmBF}_{3}-(\mathrm{AEBS})_{3}$ and ${ }^{18} \mathrm{~F}$ $\mathrm{AmBF}_{3}-(\mathrm{ABS})_{3}$ to these 2 intracellular off-target $\mathrm{CA}$ isoforms is highly unlikely. Trimerization of AEBS and ABS to form $\mathrm{AmBF}_{3}-(\mathrm{AEBS})_{3}$ and $\mathrm{AmBF}_{3}-(\mathrm{ABS})_{3}$, respectively, affords cell impermeability due to the high molecular weight $(>1 \mathrm{kDa})$. On the other hand, the high binding affinity of $\mathrm{AmBF}_{3}-(\mathrm{AEBS})_{3}$ and $\mathrm{AmBF}_{3}-(\mathrm{ABS})_{3}$ to $\mathrm{CA}-\mathrm{XII}$ is advantageous as $\mathrm{CA}-\mathrm{XII}$ is also found upregulated in hypoxic tumors (35).

Recently, we reported a facile ${ }^{18} \mathrm{~F}-{ }^{19} \mathrm{~F}$ isotopic exchange reaction on $\mathrm{AmBF}_{3}$-bioconjugates for the preparation of PET tracers (5). Features of this radiolabeling strategy include 1-step synthesis without azeotropic drying, good radiochemical yields, high purity, specific activity and in vitro/vivo stability, and relative ease of purification without high-performance liquid chromatography (5). This approach for ${ }^{18} \mathrm{~F}$ labeling has been successfully applied to RGD and somatostatin analogs for cancer imaging $(31,36)$. The $\mathrm{AmBF}_{3}$-conjugated CA-IX-targeting tracers reported here were both obtained in good radiochemical yields $(16.3 \%-36.8 \%)$ and specific activity (40-207 GBq/ $\mu \mathrm{mol})$ within $30 \mathrm{~min}$ of synthesis time. These radiosynthesis data (radiochemical yield and specific activity) are comparable with those previously reported for other $\mathrm{AmBF}_{3}$-conjugates $(31,36)$.

For in vivo evaluations, imaging and biodistribution studies were conducted with immunodeficient mice inoculated with HT-29 human colorectal cancer cells. HT-29 cells express high levels of CA-IX under hypoxic conditions (37). Biodistribution (Table 3) and PET/CT images (Figs. 4 and 5) showed that tracers cleared rapidly through the hepatobiliary and renal pathways. At $1 \mathrm{~h}$ after injection, ${ }^{18} \mathrm{~F}-\mathrm{AmBF}_{3}$ AEBS and ${ }^{18} \mathrm{~F}-\mathrm{AmBF}_{3}-\mathrm{ABS}$ had higher 
TABLE 2

CA-I, -II, -IX, and -XII Inhibition Data

\begin{tabular}{lcccc}
\hline & \multicolumn{4}{c}{$\mathrm{K}_{\mathrm{i}}(\mathrm{nM})^{\star}$} \\
\cline { 2 - 5 } Compound & CA-I & CA-II & CA-IX & CA-XII \\
\hline AmBF $_{3}$-AEBS & 137 & 27.5 & 8.0 & 0.76 \\
$\mathrm{AmBF}_{3}$-ABS & 65.6 & 59.8 & 6.6 & 0.49 \\
$\mathrm{AmBF}_{3}$-(AEBS) & 34.8 & 26.5 & 35.7 & 8.6 \\
$\mathrm{AmBF}_{3}$-(ABS) & 100.3 & 8.6 & 8.5 & 8.6 \\
Acetazolamide & 250 & 12 & 25 & 6.0
\end{tabular}

${ }^{*}$ Errors in range of $5 \%-10 \%$ of reported values from 3 different assays.

tumor accumulation $(0.56 \pm 0.11$ and $0.64 \pm 0.08 \% \mathrm{ID} / \mathrm{g})$ than their trimeric counterparts $(0.30 \pm 0.10$ and $0.33 \pm 0.07 \% \mathrm{ID} / \mathrm{g})$; however, tumor-to-background ratios were substantially lower. Most importantly, tumor-to-blood ratios were $1.01 \pm 0.25$ and $1.24 \pm 0.12$ for ${ }^{18} \mathrm{~F}-\mathrm{AmBF}_{3}-\mathrm{AEBS}$ and ${ }^{18} \mathrm{~F}-\mathrm{AmBF}_{3}-$ $\mathrm{ABS}$, respectively, suggesting that both tracers may have bound intracellular CAs in blood. Although monomers may be more pertinent for traversing through aberrant tumor vasculature and binding to CA-IX, they appear to be unable to differentiate between CA isoforms. In regards to the trimers, ${ }^{18} \mathrm{~F}-\mathrm{AmBF}_{3}-(\mathrm{ABS})_{3}$ demonstrated superior tumor-to-muscle $(9.55 \pm 2.96$ vs. $4.94 \pm 2.76)$ and tumor-to-blood $(3.93 \pm 1.26$ vs. $2.88 \pm 1.81)$ ratios. The difference may be explained by tracer lipophilicity. With 3 additional ethylene moieties, ${ }^{18} \mathrm{~F}-\mathrm{AmBF}_{3}-(\mathrm{AEBS})_{3}$ proved more lipophilic and had a higher $\log \mathrm{D}_{7.4}$ value than ${ }^{18} \mathrm{~F}-\mathrm{AmBF}_{3}-(\mathrm{ABS})_{3}$. With the exception of the testes, stomach, kidney, and bone, uptake in nontarget tissues was higher for ${ }^{18} \mathrm{~F}-\mathrm{AmBF}_{3}-(\mathrm{AEBS})_{3}$. On the basis of this observation, it appears that image contrast may be improved by selecting more hydrophilic CA-IX-targeting pharmacophores (38). Because ${ }^{18} \mathrm{~F}_{-} \mathrm{AmBF}_{3}-(\mathrm{ABS})_{3}$ yielded the most promising results of the evaluated tracers, additional biodistribution studies were performed at $2 \mathrm{~h}$ after injection to determine whether tumor uptake or contrast would improve over time. Although tumor uptake for ${ }^{18} \mathrm{~F}-\mathrm{AmBF}_{3}-(\mathrm{ABS})_{3}$ decreased slightly to $0.24 \pm 0.05 \%$ ID/g by $2 \mathrm{~h}$ after injection, tumors were readily visualized in PET images (data not shown).

Of the small-molecule inhibitors that have been radiolabeled for CA-IX imaging, only a subset has been evaluated in vivo (Table 1). Akurathi et al. reported biodistribution data for ${ }^{99 \mathrm{~m}} \mathrm{Tc}-$ labeled AEBS derivatives (compounds B-F, Table 1) in HT-29 tumor xenografts $(18,19)$. Tracers showed limited retention in tumors $(\leq 0.5 \%$ $\mathrm{ID} / \mathrm{g}$ at $0.5-4 \mathrm{~h}$ after injection) with low contrast ( $\leq 1.0$ tumor-toblood ratio). Our research group evaluated ${ }^{18} \mathrm{~F}-$ labeled U-104 (compound $\mathrm{H}$ ) (21), FEC (7-(2-fluoroethoxy)coumarin, compound $\mathrm{N}$ ) (21), and tertiary-substituted benzenesulfonamides (compound $\mathrm{K}$ )

TABLE 3

Biodistribution and Tumor-to-Nontarget Ratios for ${ }^{18} \mathrm{~F}-\mathrm{AmBF}_{3}$ Sulfonamides

\begin{tabular}{|c|c|c|c|c|c|c|c|}
\hline \multirow[b]{2}{*}{ Organ } & \multirow[b]{2}{*}{$\begin{array}{l}{ }^{18} \mathrm{~F}-\mathrm{AmBF}_{3^{-}} \\
\mathrm{AEBS}, 1 \mathrm{~h} \\
\text { after injection }\end{array}$} & \multirow[b]{2}{*}{$\begin{array}{c}{ }^{18} \mathrm{~F}-\mathrm{AmBF}_{3^{-}} \\
\mathrm{ABS}, 1 \mathrm{~h} \\
\text { after injection }\end{array}$} & \multirow[b]{2}{*}{$\begin{array}{l}{ }^{18} \mathrm{~F}-\mathrm{AmBF}_{3^{-}} \\
(\mathrm{AEBS})_{3}, 1 \mathrm{~h} \\
\text { after injection }\end{array}$} & \multicolumn{4}{|c|}{${ }^{18} \mathrm{~F}-\mathrm{AmBF}_{3}-(\mathrm{ABS})_{3}$} \\
\hline & & & & $\begin{array}{l}0.5 \mathrm{~h} \text { after } \\
\text { injection }\end{array}$ & $\begin{array}{c}1 \mathrm{~h} \text { after } \\
\text { injection, } \\
\text { unblocked }\end{array}$ & $\begin{array}{l}1 \mathrm{~h} \text { after } \\
\text { injection, } \\
\text { blocked }^{*}\end{array}$ & $\begin{array}{l}2 \mathrm{~h} \text { after } \\
\text { injection }\end{array}$ \\
\hline Blood & $0.56 \pm 0.05$ & $0.51 \pm 0.05$ & $0.19 \pm 0.20$ & $0.26 \pm 0.02$ & $0.09 \pm 0.05$ & $0.17 \pm 0.17$ & $0.07 \pm 0.01$ \\
\hline Fat & $0.08 \pm 0.03$ & $0.08 \pm 0.03$ & $0.04 \pm 0.05$ & $0.16 \pm 0.08$ & $0.02 \pm 0.01$ & $0.03 \pm 0.04$ & $0.02 \pm 0.00$ \\
\hline Testes & $0.14 \pm 0.05$ & $0.23 \pm 0.15$ & $0.04 \pm 0.05$ & $0.20 \pm 0.11$ & $0.04 \pm 0.01$ & $0.03 \pm 0.02$ & $0.03 \pm 0.00$ \\
\hline Stomach & $0.54 \pm 0.39$ & $2.32 \pm 2.14$ & $1.03 \pm 0.27$ & $4.66 \pm 4.06$ & $1.90 \pm 1.62$ & $0.26 \pm 0.36$ & $0.44 \pm 0.26$ \\
\hline Spleen & $0.38 \pm 0.03$ & $0.54 \pm 0.31$ & $0.55 \pm 0.73$ & $0.68 \pm 0.24$ & $0.37 \pm 0.34$ & $0.19 \pm 0.24$ & $0.19 \pm 0.05$ \\
\hline Liver & $10.87 \pm 0.53$ & $13.64 \pm 2.49$ & $0.98 \pm 0.67$ & $9.64 \pm 3.66$ & $0.97 \pm 0.27$ & $0.34 \pm 0.18^{\dagger}$ & $0.58 \pm 0.19$ \\
\hline Pancreas & $0.59 \pm 0.07$ & $0.57 \pm 0.18$ & $0.07 \pm 0.05$ & $0.22 \pm 0.10$ & $0.07 \pm 0.05$ & $0.08 \pm 0.11$ & $0.05 \pm 0.03$ \\
\hline Adrenals & $0.32 \pm 0.10$ & $0.54 \pm 0.27$ & $0.34 \pm 0.50$ & $0.97 \pm 1.02$ & $0.21 \pm 0.15$ & $0.08 \pm 0.03$ & $0.26 \pm 0.14$ \\
\hline Kidney & $74.33 \pm 19.64$ & $52.70 \pm 14.09$ & $0.94 \pm 0.32$ & $18.63 \pm 3.41$ & $1.78 \pm 0.49$ & $0.14 \pm 0.04^{\dagger}$ & $5.86 \pm 0.86$ \\
\hline Lungs & $0.90 \pm 0.18$ & $1.97 \pm 0.11$ & $0.48 \pm 0.54$ & $2.75 \pm 0.52$ & $0.41 \pm 0.29$ & $0.23 \pm 0.14$ & $0.24 \pm 0.04$ \\
\hline Heart & $0.29 \pm 0.04$ & $0.27 \pm 0.02$ & $0.10 \pm 0.07$ & $0.32 \pm 0.05$ & $0.08 \pm 0.04$ & $0.04 \pm 0.03$ & $0.08 \pm 0.04$ \\
\hline Muscle & $0.18 \pm 0.05$ & $0.32 \pm 0.11$ & $0.07 \pm 0.03$ & $0.26 \pm 0.08$ & $0.04 \pm 0.02$ & $0.03 \pm 0.01$ & $0.10 \pm 0.05$ \\
\hline Bone & $2.05 \pm 0.36$ & $0.85 \pm 0.11$ & $0.18 \pm 0.12$ & $0.52 \pm 0.09$ & $0.21 \pm 0.09$ & $0.10 \pm 0.04$ & $0.34 \pm 0.02$ \\
\hline Brain & $0.05 \pm 0.02$ & $0.04 \pm 0.00$ & $0.02 \pm 0.02$ & $0.09 \pm 0.02$ & $0.02 \pm 0.01$ & $0.01 \pm 0.01$ & $0.02 \pm 0.01$ \\
\hline Tumor & $0.56 \pm 0.11$ & $0.64 \pm 0.08$ & $0.30 \pm 0.10$ & $0.70 \pm 0.13$ & $0.33 \pm 0.07$ & $0.06 \pm 0.01^{\dagger}$ & $0.24 \pm 0.05$ \\
\hline Tumor-to-liver & $0.05 \pm 0.01$ & $0.05 \pm 0.01$ & $0.37 \pm 0.14$ & $0.07 \pm 0.03$ & $0.35 \pm 0.07$ & $0.19 \pm 0.04^{\dagger}$ & $0.42 \pm 0.07$ \\
\hline Tumor-to-blood & $1.01 \pm 0.25$ & $1.24 \pm 0.12$ & $2.88 \pm 1.81$ & $2.74 \pm 0.68$ & $3.93 \pm 1.26$ & $1.08 \pm 1.03^{\dagger}$ & $3.53 \pm 0.55$ \\
\hline Tumor-to-muscle & $3.18 \pm 0.63$ & $2.15 \pm 0.66$ & $4.94 \pm 2.76$ & $2.87 \pm 1.43$ & $9.55 \pm 2.96$ & $1.95 \pm 0.52^{\dagger}$ & $2.78 \pm 1.44$ \\
\hline
\end{tabular}

*Blocked by preinjection of $10 \mathrm{mg}$ of acetazolamide per kilogram $1 \mathrm{~h}$ before radiotracer administration.

${ }^{\dagger}$ Preinjection significantly reduced uptake of same organ/ratio $(P<0.05)$.

Values are mean $\pm \operatorname{SD}(n \geq 4)$. 

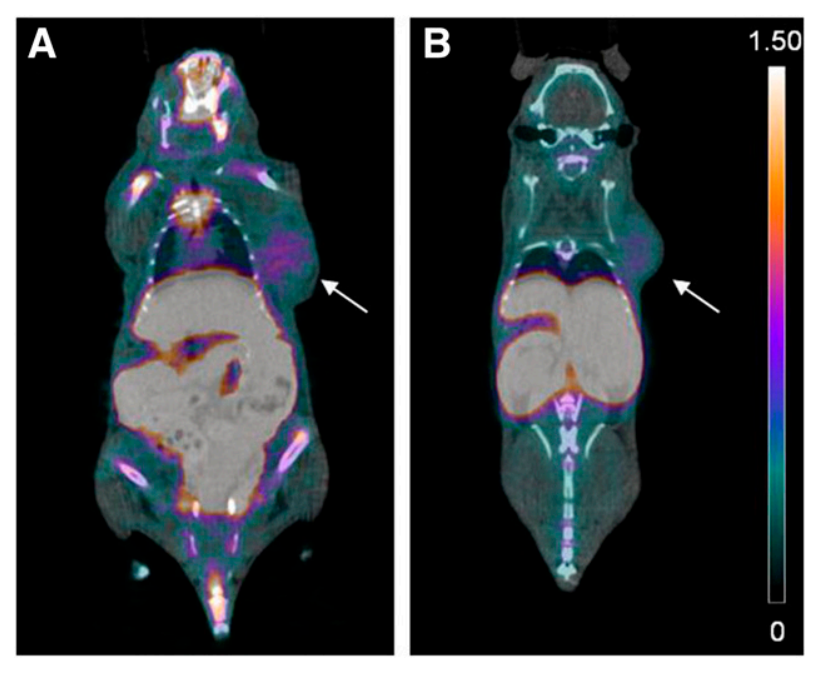

FIGURE 4. PET/CT images of monomeric ${ }^{18} \mathrm{~F}$-sulfonamides at $1 \mathrm{~h}$ after injection of ${ }^{18} \mathrm{~F}-\mathrm{AmBF}_{3}$-AEBS $(\mathrm{A})$ and ${ }^{18} \mathrm{~F}-\mathrm{AmBF}_{3}-\mathrm{ABS}(\mathrm{B})$. Tumors are indicated by arrows. Scale bar unit is \%ID/g.

(20) as CA-IX imaging agents. U-104 suffered from isoform selectivity, whereas FEC and tertiary-substituted benzenesulfonamides lacked stability in vivo. ${ }^{18} \mathrm{~F}-\mathrm{VM} 4-037$ (compound I), an ethoxzolamide derivative developed by Siemens, is the only radiolabeled small-molecule inhibitor that advanced to phase I clinical trial (17). Biodistribution and dosimetry studies in healthy volunteers showed high uptake in the liver and kidneys, with minimal clearance. The authors noted that the pharmacokinetics of ${ }^{18} \mathrm{~F}-\mathrm{VM} 4-037$ will preclude its use for imaging lesions in these organs and that pathologic studies correlating ${ }^{18} \mathrm{~F}-\mathrm{VM} 4-037 \mathrm{up}-$ take and intratumoral CA-IX expression were required. Interestingly, Peeters et al. recently published preclinical biodistribution/ imaging data for ${ }^{18} \mathrm{~F}-\mathrm{VM} 4-037$, with the tracer failing to detect CA-IX expression in either glioma or colorectal cancer xenograft models (39).

Given the prognostic and therapeutic value of CA-IX, the development of CA-IX imaging agents will have a significant clinical impact. Notwithstanding somewhat low tumor uptake, both ${ }^{18} \mathrm{~F}$ $\mathrm{AmBF}_{3}-(\mathrm{AEBS})_{3}$ and ${ }^{18} \mathrm{~F}-\mathrm{AmBF}_{3}-(\mathrm{ABS})_{3}$ enabled clear visualization of CA-IX-expressing HT-29 tumor xenografts to provide some of the highest tumor-to-blood and tumor-to-muscle ratios ever reported. Preinjection of acetazolamide significantly blocked tumor uptake to near-background levels for ${ }^{18} \mathrm{~F}-\mathrm{AmBF}_{3}-(\mathrm{ABS})_{3}$, demonstrating target specificity. These data represent a great advancement over previous attempts and demonstrate the effectiveness of increasing cell impermeability to achieve CA-IX selectivity. Further synthetic modifications to reduce gastrointestinal uptake and the use of more specific inhibitors to increase tumor uptake are ongoing. In the meantime, we suggest that this method has great potential to enhance in vivo imaging of extracellular enzymatic activity through the simple application of a multivalent approach that mitigates generalized uptake.

\section{CONCLUSION}

We synthesized and evaluated four ${ }^{18} \mathrm{~F}$-labeled sulfonamides as PET imaging agents targeting CA-IX. Trimerization of sulfonamide derivatives successfully conferred $\mathrm{CA}$ isoform selectivity in vivo. ${ }^{18} \mathrm{~F}-\mathrm{AmBF}_{3}-(\mathrm{ABS})_{3}$ showed specific and selective uptake in CA-IX-expressing tumor xenografts with good contrast. The use of multivalent enzyme inhibitors represents a viable strategy to selectively image extracellular enzyme activity with PET.

\section{DISCLOSURE}

The costs of publication of this article were defrayed in part by the payment of page charges. Therefore, and solely to indicate this fact, this article is hereby marked "advertisement" in accordance with 18 USC section 1734 . This work was supported by the Canadian Cancer Society, the Canadian Institutes of Health Research, and the Leading Edge Endowment Fund, including a Rix Family scholarship. No other potential conflict of interest relevant to this article was reported.

\section{ACKNOWLEDGMENTS}

We thank Navjit Hundal-Jabal, Nadine Colpo, Milan Vuckovic, Wade English, and Julius Klug for technical assistance.
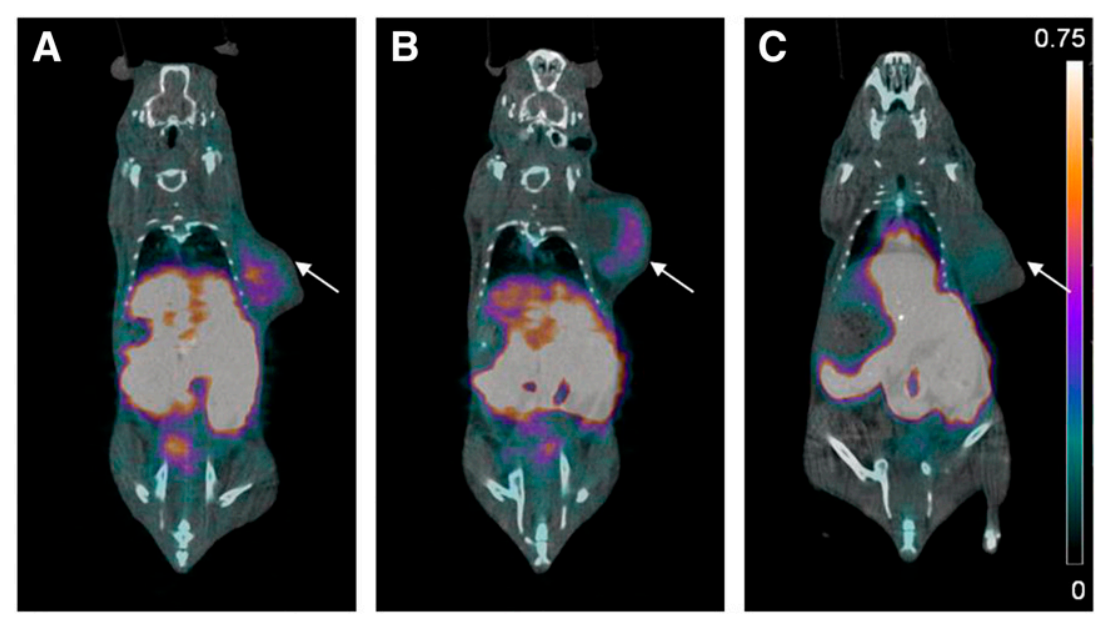

FIGURE 5. PET/CT images of trimeric ${ }^{18} \mathrm{~F}$-sulfonamides at $1 \mathrm{~h}$ after injection of ${ }^{18} \mathrm{~F}-\mathrm{AmBF}_{3}$ $(\mathrm{AEBS})_{3}(\mathrm{~A}),{ }^{18} \mathrm{~F}-\mathrm{AmBF}_{3}-(\mathrm{ABS})_{3}(\mathrm{~B})$, and ${ }^{18} \mathrm{~F}_{-} \mathrm{AmBF}_{3}-(\mathrm{ABS})_{3}(\mathrm{C})$ preblocking with acetazolamide. Tumors are indicated by arrows. Scale bar unit is $\% \mathrm{ID} / \mathrm{g}$.

\section{REFERENCES}

1. Kniess T, Laube M, Bergmann R, et al. Radiosynthesis of a ${ }^{18} \mathrm{~F}$-labeled 2,3-diarylsubstituted indole via McMurry coupling for functional characterization of cyclooxygenase-2 (COX-2) in vitro and in vivo. Bioorg Med Chem. 2012;20:3410-3421.

2. Vasdev N, Dorff PN, O'Neil JP, Chin FT, Hanrahan S, VanBrocklin HF. Metabolic stability of 6,7-dialkoxy-4-(2-, 3- and 4-[ $\left.{ }^{18} \mathrm{~F}\right]$ fluoroanilino) quinazolines, potential EGFR imaging probes. $\mathrm{Bi}$ oorg Med Chem. 2011;19:2959-2965.

3. Liu H, Liu S, Miao Z, et al. Development of ${ }^{18} \mathrm{~F}$ labeled picolinamide probes for PET imaging of malignant melanoma. J Med Chem. 2013;56:895-901.

4. Cai LS, Shuiyu L, Pike VW. Chemistry with $\left[{ }^{18} \mathrm{~F}\right]$ fluoride ion. Eur J Org Chem. 2008;2008:2853-2873.

5. Liu Z, Pourghiasian M, Radtke MA, et al. An organotrifluoroborate for broadly applicable one-step ${ }^{18}$ F-labeling. Angew Chem Int Ed Engl. 2014;53: 11876-11880.

6. Supuran CT. Carbonic anhydrases: novel therapeutic applications for inhibitors and activators. Nat Rev Drug Discov. 2008;7:168-181. 
7. Supuran CT. Inhibition of carbonic anhydrase IX as a novel anticancer mechanism. World J Clin Oncol. 2012;3:98-103.

8. Robertson N, Potter C, Harris AL. Role of carbonic anhydrase IX in human tumor cell growth, survival, and invasion. Cancer Res. 2004;64:6160-6165.

9. Swietach P, Hulikova A, Vaughan-Jones RD, Harris AL. New insights into the physiological role of carbonic anhydrase IX in tumour $\mathrm{pH}$ regulation. Oncogene. 2010;29:6509-6521.

10. Lock FE, McDonald PC, Lou Y, et al. Targeting carbonic anhydrase IX depletes breast cancer stem cells within the hypoxic niche. Oncogene. 2013;32:52105219.

11. McDonald PC, Dedhar S. Carbonic anhydrase IX (CAIX) as a mediator of hypoxia-induced stress response in cancer cells. Subcell Biochem. 2014;75: 255-269.

12. Liao SY, Lerman MI, Stanbridge EJ. Expression of transmembrane carbonic anhydrases, CAIX and CAXII, in human development. BMC Dev Biol. 2009; $9: 22$.

13. Karhumaa P, Kaunisto K, Parkkila S, et al. Expression of the transmembrane carbonic anhydrases, CA IX and CA XII, in the human male excurrent ducts. Mol Hum Reprod. 2001;7:611-616.

14. Saarnio J, Parkkila S, Parkkila AK, et al. Immunohistochemistry of carbonic anhydrase isozyme IX (MN/CA IX) in human gut reveals polarized expression in the epithelial cells with the highest proliferative capacity. J Histochem Cytochem. 1998;46:497-504.

15. Divgi CR, Uzzo RG, Gatsonis C, et al. Positron emission tomography/computed tomography identification of clear cell renal cell carcinoma: results from the REDECT trial. J Clin Oncol. 2013;31:187-194.

16. Apte SD, Chin FT, Graves EE. Synthesis of a new PET radiotracer targeting carbonic anhydrase IX. J Labelled Comp Radiopharm. 2009;52:S408.

17. Doss M, Kolb HC, Walsh JC, et al. Biodistribution and radiation dosimetry of the carbonic anhydrase IX imaging agent $\left[{ }^{18} \mathrm{~F}\right] \mathrm{VM} 4-037$ determined from PET/CT scans in healthy volunteers. Mol Imaging Biol. 2014;16:739-746.

18. Akurathi V, Dubois L, Celen S, et al. Development and biological evaluation of ${ }^{99 \mathrm{~m}} \mathrm{Tc}$-sulfonamide derivatives for in vivo visualization of CA IX as surrogate tumor hypoxia markers. Eur J Med Chem. 2014;71:374-384.

19. Akurathi V, Dubois L, Lieuwes NG, et al. Synthesis and biological evaluation of a ${ }^{99 \mathrm{~m} T c-l a b e l l e d ~ s u l f o n a m i d e ~ c o n j u g a t e ~ f o r ~ i n ~ v i v o ~ v i s u a l i z a t i o n ~ o f ~ c a r b o n i c ~}$ anhydrase IX expression in tumor hypoxia. Nucl Med Biol. 2010;37:557-564.

20. Lau J, Pan J, Zhang Z, et al. Synthesis and evaluation of ${ }^{18} \mathrm{~F}$-labeled tertiary benzenesulfonamides for imaging carbonic anhydrase IX expression in tumours with positron emission tomography. Bioorg Med Chem Lett. 2014;24:3064-3068.

21. Pan J, Lau J, Mesak F, et al. Synthesis and evaluation of ${ }^{18} \mathrm{~F}$-labeled carbonic anhydrase IX inhibitors for imaging with positron emission tomography. $J$ Enzyme Inhib Med Chem. 2014;29:249-255.

22. Asakawa C, Ogawa M, Kumata K, et al. Radiosynthesis of three $\left[{ }^{11} \mathrm{C}\right]$ ureidosubstituted benzenesulfonamides as PET probes for carbonic anhydrase IX in tumors. Bioorg Med Chem Lett. 2011;21:7017-7020.

23. Lu G, Hillier SM, Maresca KP, et al. Synthesis and SAR of novel Re/ ${ }^{99 \mathrm{~m}} \mathrm{Tc}-$ labeled benzenesulfonamide carbonic anhydrase IX inhibitors for molecular imaging of tumor hypoxia. J Med Chem. 2013;56:510-520.
24. Can D, Spingler B, Schmutz P, et al. [(Cp-R)M(CO)3] $\left(M=R e\right.$ or $\left.{ }^{99 m} \mathrm{Tc}\right)$ Arylsulfonamide, arylsulfamide, and arylsulfamate conjugates for selective targeting of human carbonic anhydrase IX. Angew Chem Int Ed Engl. 2012;51:3354-3357.

25. Geers C, Gros G. Carbon dioxide transport and carbonic anhydrase in blood and muscle. Physiol Rev. 2000;80:681-715.

26. Ahlskog JK, Dumelin CE, Trussel S, Marlind J, Neri D. In vivo targeting of tumor-associated carbonic anhydrases using acetazolamide derivatives. Bioorg Med Chem Lett. 2009;19:4851-4856.

27. Dubois L, Douma K, Supuran CT, et al. Imaging the hypoxia surrogate marker CA IX requires expression and catalytic activity for binding fluorescent sulfonamide inhibitors. Radiother Oncol. 2007;83:367-373.

28. Wilkinson BL, Bornaghi LF, Houston TA, Innocenti A, Supuran CT, Poulsen SA. A novel class of carbonic anhydrase inhibitors: glycoconjugate benzene sulfonamides prepared by "click-tailing." J Med Chem. 2006;49:6539-6548.

29. Cecchi A, Hulikova A, Pastorek J, et al. Carbonic anhydrase inhibitors: design of fluorescent sulfonamides as probes of tumor-associated carbonic anhydrase IX that inhibit isozyme IX-mediated acidification of hypoxic tumors. J Med Chem. 2005;48:4834-4841.

30. Dubois L, Peeters S, Lieuwes NG, et al. Specific inhibition of carbonic anhydrase IX activity enhances the in vivo therapeutic effect of tumor irradiation. Radiother Oncol. 2011;99:424-431.

31. Liu Z, Radtke MA, Wong MQ, Lin KS, Yapp DT, Perrin DM. Dual mode fluorescent ${ }^{18} \mathrm{~F}$-PET tracers: efficient modular synthesis of rhodamine-[cRGD] $2-\left[{ }^{18} \mathrm{~F}\right]$-organotrifluoroborate, rapid, and high yielding one-step ${ }^{18} \mathrm{~F}$-labeling at high specific activity, and correlated in vivo PET imaging and ex vivo fluorescence. Bioconjug Chem. 2014;25:1951-1962.

32. Vullo D, Franchi M, Gallori E, et al. Carbonic anhydrase inhibitors: inhibition of the tumor-associated isozyme IX with aromatic and heterocyclic sulfonamides. Bioorg Med Chem Lett. 2003;13:1005-1009.

33. Thiry A, Ledecq M, Cecchi A, et al. Ligand-based and structure-based virtual screening to identify carbonic anhydrase IX inhibitors. Bioorg Med Chem. 2009;17:553-557.

34. Temperini C, Innocenti A, Scozzafava A, Parkkila S, Supuran CT. The coumarinbinding site in carbonic anhydrase accommodates structurally diverse inhibitors: the antiepileptic lacosamide as an example and lead molecule for novel classes of carbonic anhydrase inhibitors. J Med Chem. 2010;53:850-854.

35. Pastorekova S, Zatovicova M, Pastorek J. Cancer-associated carbonic anhydrases and their inhibition. Curr Pharm Des. 2008;14:685-698.

36. Liu Z, Pourghiasian M, Benard F, Pan J, Lin KS, Perrin DM. Preclinical evaluation of a high-affinity ${ }^{18} \mathrm{~F}$-trifluoroborate octreotate derivative for somatostatin receptor imaging. J Nucl Med. 2014;55:1499-1505.

37. Carlin S, Khan N, Ku T, Longo VA, Larson SM, Smith-Jones PM. Molecular targeting of carbonic anhydrase IX in mice with hypoxic HT29 colorectal tumor xenografts. PLoS One. 2010;5:e10857.

38. Rami M, Dubois L, Parvathaneni NK, et al. Hypoxia-targeting carbonic anhydrase IX inhibitors by a new series of nitroimidazole-sulfonamides/sulfamides/ sulfamates. J Med Chem. 2013;56:8512-8520.

39. Peeters SG, Dubois L, Lieuwes NG, et al. $\left[{ }^{18}\right.$ F]VM4-037 MicroPET imaging and biodistribution of two in vivo caix-expressing tumor models. Mol Imaging Biol. February 24, 2015 [Epub ahead of print]. 